\title{
UN EJERCICIO DE PROGRAMACION FINANCIERA MUNICIPAL
}

336.121:301.175.6

\section{por \\ Alberto de Rovira Mola \\ Doctor en Derecho. Jefe del Departamento de Programación} del Ayuntamiento de Barcelona

\section{y}

\section{Javier Merino Martínez}

Licenciado en Ciencias Económicas. Técnico del Departamento de Programación del Ayuntamiento de Barcelona

SUMARIO: I. JUSTIFICACION.-II. INTRODUCCION: 1. PREMISAS. 2. PRECISIONES TERMINOLOGICAS Y CONCEPTUALES. - III. ANALISIS RETROSPECTIVO: 1. INDICADORES Y SITUACIÓN DE PARTIDA. 2. RELACIÓN ENTRE ENDEUDAMIENTO Y RENTA LOCAL. 3. RELACIÓN ENTRE CARGA DE LA

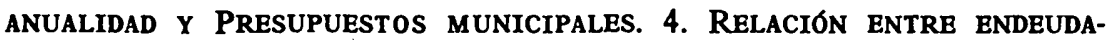
Miento $Y$ PResupuestos municipales. 5. Relación ENTRE ENDEUdaMIENTO Y CARGA FINANCIERA. - IV. ANALISIS PROSPECTIVO: DETERMINACION DE LA CAPACIDAD POTENCIAL DE RECURSOS FINANCIEROS: 1. ESQUEMA OPERATIVO. 2. RESUlTadOS.-V. CORRECCION DEL MODELO.-VI. CONCLUSION.

\section{JUSTIFICACION}

La reciente publicación de un interesante trabajo sobre los problemas relativos al establecimiento de planes financieros a plazo medio en los Municipios (1), así como algunos quehaceres profesionales últimamente cumplidos, nos han concitado a redactar el presente ejercicio de programación financiera municipal. Su pretensión es modesta y se ciñe casi exclusivamente al intento de

(1) Vid. Dr. Helfried BAuER: aLa planificación financiera municipal en Austrias, en Boletín Bimestral Informativo (Banco de Crédito Local de España), 1974, número 15, páginas 46-51. 
demostrar, con modelos basados en datos reales y con un procedimiento sencillo, la viabilidad de dicha programación.

Ciertamente, en el ordenamiento local español sólo en los regímenes especiales de Barcelona y de Madrid constan prevenciones legales concernientes a la planificación financiera municipal (2). Y el Proyecto de Ley de Bases del Estatuto del Régimen Local - pendiente ante las Cortes cuando se escriben estas líneas- no contiene al respecto ninguna previsión específica, aunque naturalmente podría incluirla el futuro texto articulado al que se refiere la disposición final primera de dicho Proyecto de Ley. Un indicio para esta suposición lo facilita la base 35 del mismo, que menciona el propósito prenormativo de introducir el sistema de Presupuesto único en el ámbito de las Corporaciones locales (3).

Pero la ausencia de mandato legal no disminuye la notoria conveniencia - que en muchos casos se acerca a la necesidad y aun se identifica con ella- de llevar a cabo los oportunos estudios de programación financiera, pese al escepticismo que todavía suscitan en personas vinculadas a la Administración local. Si se tiene en cuenta que el objetivo principal perseguido con la implantación de una planificación financiera a medio plazo consiste en la coordinación de la actividad inversora municipal con las posibilidades financieras, es decir, por un lado, aprovechar hasta un límite máximo el margen de endeudamiento y, por el otro, asegurar a plazo medio la liquidez y el equilibrio presupuestario, se llega a la convicción de aquella conveniencia o necesidad. La planificación financiera municipal, como manifestación singular del análisis económico-financiero en las Entidades locales, ofrece a los responsables de la gestión de los intereses comunales la oportunidad de juzgar, con amplios elementos de juicio y sobre la base de soluciones alterna-

(2) Evidentemente, sólo en un sentido metafórico cabria hablar de planificación financiera en relación con las normas presupuestarias contenidas en los artículos 676, a) y b), y 677, a) y c), de la vigente Ley de Régimen local. En cambio, vid. artículos 32, c), y 33-1 del Texto articulado de la Ley de Régimen especial para el Municipio de Barcelona, aprobado por el Decreto 1.166, de 23 de mayo de 1960 , y 62-2, d), y 65-2, 2. ${ }^{\circ}$, del Reglamento aprobado por el Decreto 4.026/1964, de 3 de diciembre, y artículo 42-1, c), del Texto articulado de la Ley de Régimen especial para el Municipio de Madrid, aprobado por el Decreto de 1 de julio de 1963, número $1.964 / 1963$.

(3) Base 35-1: «Las Corporaciones locales formarán para cada ejercicio económico un único Presupuesto. Las inversiones que se financien con operaciones de crédito requerirán la aprobación del Ministerio de Hacienda, sin perjuicio de incluir en cada Presupuesto la anualidad a ejecutar en el ejercicios (Texto utilizado: Bases del Estatuto del Régimen local. Proyecto de Ley. Madrid, Instituto de Estudios de Administración Local, 1974, página 114). 
tivas, la situación actual de la Entidad, como obligado antecedente para adoptar decisiones para el futuro (4).

\section{INTRODUCCION}

\section{PREM ISAS}

Para realizar el presente ejercicio hemos adoptado como hipótesis de trabajo el de un Municipio en el que concurren las características y circunstancias resumidas a continuación:

a) Con un censo de unos 150.000 habitantes, ha experimentado en los últimos años una expansión muy acentuada, incrementándose notablemente la industrialización y la edificación.

b) Esta expansión -mayor cifra de población, densidad demográfica más alta y urbanización más amplia-, con independencia de posibles economías o deseconomías de escala, ha exigido cuantiosas inversiones en infraestructura y equipo social, financiadas - prescindiendo, para simplificar, de subvenciones especiales del Estado- con recursos ordinarios, sobre todo a través del Presupuesto especial de Urbanismo, y con préstamos del Banco de Crédito Local de España.

c) El Ayuntamiento de dicho Municipio, percatado de los halagüeños resultados de la dinámica actuación emprendida y consciente de las posibilidades de un endeudamiento más elevado, quiere acelerar el proceso de urbanización y de equipamiento, dentro de los límites permitidos por un sano equilibrio presupuestario y a reserva, naturalmente, de que el Banco de Crédito Local pudiera facilitarle los fondos que la potencialidad financiera de la Corporación municipal fuera capaz de soportar.

\section{PRECISIONES TERM INOLÓGICAS Y CONCEPTUALES}

Hemos adoptado la siguiente terminología:

a) endeudamiento: cantidad pendiente de devolución o amortización por razón de los préstamos concertados con el Banco de

(4) Vid. Seminarios y Simposios de Investigación 1972. Conclusiones. Madrid, Instituto de Estudios de Administración Local, 1973, página 169, conclusión 1.2 del XXX Seminario de Investigación, «El análisis económico-financiero en las Entidades locales. 
Crédito Local de España; es decir, volumen de deuda viva o pasivo de la Corporación (E) (5);

b) carga de la anualidad: monto total de intereses y de cuotas de amortización que el Ayuntamiento debe satisfacer cada año al Banco de Crédito Local (CA), y que puede distinguirse, como veremos más adelante, en carga potencial, comprometida y activa o diferencial. Comprende los gastos consignados en los capítulos IV (Deuda) y VI, artículos $3 .^{\circ}$ al $6 .^{\circ}$, de la actual estructura presupuestaria de las Corporaciones locales;

c) carga financiera: importe de los intereses que la Corporación ha de pagar cada año a dicho Banco (CF) (6);

ch) Presupuestos municipales: suma del Presupuesto ordinario (PO) y del Presupuesto especial de Urbanismo (PU) por sus importes netos, es decir, una vez eliminada la aportación del primero al último (PM) (7);

d) renta local: fracción de la renta nacional producida por los habitantes del Municipio (RL);

e) esfuerzo presupuestario: porcentaje que los Presupuestos municipales (PM) representan respecto a la renta local de un año determinado (RP);

f) gasto corriente: gasto municipal consignado en los capítulos I, II, III, V y VII de la actual estructura presupuestaria de las Corporaciones locales, esto es, "personal», "material y diversos", "clases pasivas», «subvenciones y participaciones en ingresos» y «reintegrables, indeterminados e imprevistos" (GC), y

g) inversión real: gasto municipal consignado en el capítulo VI, artículos $10^{\circ}$ y $2 .^{\circ}$ (inversoras no productoras y productoras de ingresos, respectivamente), y que puede estar financiado con recursos ordinarios (IRO) y/o con recursos extraordinarios procedentes del crédito local (IRE).

(5) Para simplificar el ejercicio, se supone que el único acreedor del Ayuntamiento es el Banco de Crédito Local de España.

(6) Sobre el concepto de acarga financieras y su distinción del aendeudamienton, vid. el interesante trabajo de Alberto Piñero Guilamany: aUn elemento fundamental en la programación de los ingresos: la carga financiera». Comunicación presentada al I Simposio de Experiencias y Proyectos, «Planificación, Programación, Presupuesto y Controls, y publicada en Rafael BarRIL Dosset: El sistema integrado de gestión. Madrid, Instituto de Estudios de Administración Local, 1973, páginas 387-398.

(7) A los efectos de simplificación, suponemos que las liquidaciones presupuestarias -en cuanto al análisis prospectivo- están niveladas en gastos e ingresos. Por otro lado, la aportación del Presupuesto ordinario al Presupuesto especial de Urbanismo representa, en términos reales, un porcentaje sobre el primero del 9 por 100. 


\section{ANALISIS RETROSPECTIVO}

\section{INDICADORES Y SITUACIÓN DE PARTIDA}

La situación financiera de la Corporación municipal se presenta con arreglo a cuatro indicadores, con el propósito de detectar no sólo la carga de la anualidad en el complejo presupuestario, sino también su incidencia en la economía local y la existencia de una capacidad infrautilizada de endeudamiento. Dichos indicadores son:

a) relación entre endeudamiento y renta local;

b) relación entre carga de la anualidad y Presupuestos municipales;

c) relación entre endeudamiento y Presupuestos municipales, y

d) relación entre endeudamiento y carga financiera.

La situación de partida se expresa en los siguientes datos de base:

a) Tabla 1.-Registra las liquidaciones presupuestarias de una serie histórica de siete ejercicios, y de ellas resulta su crecimiento, entre el año inicial y el final, del 204,2 por 100. Los incrementos de un año a otro son irregulares, pero para el análisis prospectivo se ha adoptado la tasa anual y acumulativa del 20,4 por 100 .

b) Tabla 2.-Acopia los importes totales de la tabla 1 desagregados en los tres componentes de gasto corriente, carga de la anualidad - con distinción, a su vez, de intereses y amortizaciones- e inversión real. Importa, a los efectos de este estudio, retener:

- El gasto corriente, cuyo ćrecimiento es superior al del conjunto presupuestario (285 frente a 204,2), tiende a absorber el 80 por 100 de los gastos totales. Este índice será utilizado en el análisis prospectivo.

- A medida que aumenta la carga de la anualidad, disminuye lógicamente la inversión real financiada con recursos ordinarios, cuya importancia porcentual pasa del 19 por 100 en el año 1 al 12,2 por 100 en el año 7. Paralelamente, ha aumentado en el Municipio considerado la inversión financiada con crédito local a través de Presupuestos extraordinarios.

c) Tabla 3.- Relaciona los préstamos contratados con el Banco de Crédito Local de España durante los años 1 al 7, todos a largo 
plazo, bajo el mismo tipo de interés $(7,25$ por 100$)$ y con períodos de amortización de diecinueve años en los casos de abastecimiento de aguas y saneamiento y de quince años en los demás (8). El detalle de la tabla 3 aparece resumido en «carga de la anualidad» de la tabla 2.

\section{RELACión ENTRE ENDEUdAMIENTO Y RENTA LOCAL}

El examen de la tabla 4 permite constatar, sin necesidad de verificarla, la inexistencia de correlación entre el aumento del endeudamiento y el de la renta local. La variación de la relación de un año a otro se produce como consecuencia de circunstancias ajenas a motivaciones de carácter económico en sentido estricto, y que son el resultado de un mayor o menor esfuerzo requerido por las necesidades de infraestructura y equipo social del Municipio en cuestión.

Ante la dificultad de dar una significación precisa a la relación entre endeudamiento y renta local, se podría pensar que el estudio de la ratio conduciría a encontrar en ella el techo aconsejable de endeudamiento. Sin embargo, no se pueden formular razonamientos plausibles a esta noción de límite y parece más oportuno enfocar el problema de forma inversa: en vez de indagar si el nivel máximo de endeudamiento se alcanza cuando representa un cierto porcentaje de la renta lccal, convendría plantearse si es el volumen de la renta local el tope que cercena las posibilidades de expansión del endeudamiento.

Desde este punto de vista, la expansión del endeudamiento se encuentra frenado cuando el ahorro disponible para suscribir los préstamos públicos es insuficiente o cuando éstos absorben una parte del ahcrro necesario para la inversión privada. Como la in-

(8) Hemos corregido los datos reales para adaptarlos a la información contenida en las siguientes fuentes: a) la obra colectiva El Crédito Local en España. Introducción y selección de Santiago UdiNa MaRToRel.L. Madrid, Instituto de Estudios Fiscales, Ministerio de Hacienda, 1972, especialmente páginas 251 y siguientes; b) Santiago Udina Martorell: «Bancos de Crédito Localn. Ponencia presentada al VIII Seminario Universitario Interamericano sobre Asuntos Municipales (Málaga, 1972), publicada en VIII Seminario... Madrid, Instituto de Estudios de Administración Local, 1973, páginas 81-111, y en Boletín Bimestral Informativo (Banco de Crédito Local de España), 1973, número 11, págìnas 67-85, y c) «Banco de Crédito Localn, en Boletin de Información de la Vida Local, 1974, número 82, páginas 46. Singularmente, para hacer más sencillos los cálculos, no hemos tomado en consideración ningún año de carencia ni las comisiones aplicadas por el Banco. 
versión pública obedece más a móviles de productividad que de rentabilidad, no se debe menospreciar la influencia de los tipos de interés. Si el crédito público no tiene aceptación, la Corporación se verá obligada a ofrecer tipos cada vez más altos.

En la hipótesis elegida, el Ayuntamiento no ha acudido al mercado de capitales, sino solamente al Banco de Crédito Local, por lo que tiene mayor significación hacer observar que una actuación municipal basada en el crédito público "a chorro» corre el riesgo de inquietar respecto a la solidez financiera de la Corporación o a la gestión económica de la misma. Esa actuación podría ser vigilada correctamente a través de una relación como la establecida en la tabla 4. La relación A/B crece suavemente de 0,015 a 0,044 en el último año de la serie analizada, pero descendería a partir de dicho año si no se produjeran nuevos endeudamientos. El descenso vendría condicionado por la tasa de crecimiento de la renta local, es decir, al aumentar el denominador de la relación, manteniéndose constante el numerador, la relación tendería a cero.

\section{Relación entre carga de la anualidad y Presupuestos MUNICIPALES}

El indice determinado por la relación entre la carga de la anualidad y los Presupuestos municipales constituye el instrumento más importante para medir el grado de sanidad financiera de la actuación pública municipal.

Al tratar de delimitar el contenido de la "carga de la anualidad» importa consignar dos precisiones. En primer lugar, el aspecto relativo de su magnitud. La carga de la anualidad en términos absolutos no indica nada, pues, por ejemplo, una carga de 200 millones, que sería tal vez excesiva para un Municipio de 10.000 habitantes, sería pobre y significaría una infrautilización de recursos financieros para otro de un millón de habitantes. En segundo lugar, debe recordarse que a falta de cualquier determinación legal al respecto, los Ayuntamientos españoles suelen presentar la carga de la anualidad por referencia al estado de gastos del Presupuesto ordinario, ya que la realidad demuestra que, con escasísimas excepciones, sólo dicho Presupuesto incluye la citada carga. Este es también el caso de la Corporación elegida para el presente ejercicio, pero, con fines informativos, presentamos también la carga de la anualidad en re- 
lación a los Presupuestos municipales (PM) en conjunto (tablas 5 y 6).

En la tabla 5 la relación A/B por 100 crece paulatinamente hasta alcanzar su cota máxima en el último año de la serie histórica, como consecuencia lógica de las necesidades, en alguna parte satisfechas, de inversión en infraestructura y equipo social. Pese a este paulatino endeudamiento, la cota máxima de 9,20 por 100 en el último año del período indica una infrautilización de recursos "vía crédito», y más aún si se tiene en cuenta el límite del 25 por 100 sobre el Presupuesto ordinario adoptado en general por el Banco de Crédito Local de España. En la serie histórica (tabla 2) se ha constatado que el gasto corriente tiende a situarse en torno a un 80 por 100 de los Presupuestos municipales y, por consiguiente, a un porcentaje algo inferior (75 por 100) respecto al Presupuesto ordinario. Así, el conjunto formado por el gasto corriente y la carga de la anualidad comprometida deja un excedente que puede tener un doble destino: financiar inversión real con recursos ordinarios o pagar cargas de la anualidad derivadas de una expansión del endeudamiento.

Análogas consideraciones cabe inferir de la tabla 6.

\section{Relación entre endeudamiento y Presupuestos municipales}

Según doctrina muy autorizada, que ha sido recibidà en el ámbito de la Administración local, el monto del endeudamiento, es decir, el capital pendiente de devolución o amortización, debería guardar proporción con el potencial de ingresos ordinarios de la Corporación. En relación al importe anual de dichos recursos, el volumen del endeudamiento podría llegar a ser, como máximo, tres veces superior, lo que, en otros términos, significaría que sería necesario destinar los recursos ordinarios de tres ejercicios para enjugar totalmente las amortizaciones (9).

Conforme al criterio expuesto, se puede comprobar en la tabla 7 que la relación más alta es de 2,43 , lo que representa que con los ingresos de un solo ejercicio ya se podría cubrir holgadamente el endeudamiento agregado. Ello corrobora lo indicado en el apartado

(9) Vid. conclusión 22-2 del XXX Seminario de Investigación citado en nota (4), páginas $184-185$. 
anterior acerca de las posibilidades de expansionar el endeudamiento con plena garantía de cumplir las obligaciones financieras surgidas del mismo.

\section{RELACIÓN ENTRE ENDEUDAMIENTO Y CARGA FINANCIERA}

Es evidente que la elevación del nivel de endeudamiento incrementa la carga financiera. De ahí que los tipos a los cuales hayan sido contratados los préstamos sean un elemento determinante de la magnitud de dicha carga. Conviene anotar, de otro lado, que los cambios en la estructura del endeudamiento explican en parte las variaciones de los gastos que supone. En efecto, cualquier modalidad de deuda flotante hace disminuir la carga financiera, por ser menos onerosa que la deuda a corto plazo.

La tabla 8 ofrece el resultado de la relación. La constancia de la misma durante el período considerado indica la inexistencia de cambios en la estructura del endeudamiento. En efecto, los préstamos contratados entre los años 1 al 7 han sido a largo plazo (diecinueve o quince años) y a un tipo de interés uniforme del 7,25 por 100. Es decir, el tipo ha venido condicionado por los préstamos a largo plazo, como se había supuesto en la hipótesis inicial. Luego el endeudamiento a largo plazo ha tenido, en este caso, un peso del 100 por 100 .

\section{ANALISIS PROSPECTIVO: DETERMINACION DE LA CAPACIDAD POTENCIAL DE RECURSOS FINANCIEROS}

\section{ESQUEMA OPERATIVO}

Con la finalidad, indicada anteriormente, de acelerar en lo posible el proceso de urbanización y de equipamiento del Municipio, el Ayuntamiento acuerda elaborar un plan financiero para programar las inversiones necesarias en infraestructura y equipo, y que serían realizadas en función de los recursos previsibles y en las anualidades determinadas en el plan. A la vista de los re. sultados del análisis retrospectivo, el Ayuntamiento quiere maximizar la aplicación de los ingresos ordinarios disponibles para inversión real. 
A la consecución de tal objetivo responde esta segunda parte del ejercicio, encaminada a determinar la capacidad potencial de recursos municipales disponibles, sin prejuzgar la posterior asignación de los mismos ni su grado de utilización, más o menos intensiva, lo cual sería objeto de un programa de inversiones.

Para desarrollar el ejercicio hemos adoptado el siguiente esquema operativo:

a) período considerado: siete años, o sea, el mismo lapso temporal tomado en consideración en el análisis retrospectivo;

b) renta local: sobre la base del año 7 , se ha aplicado una tasa anual y acumulativa del 7 por 100 ;

c) Presupuestos municipales: se ha aplicado el índice de crecimiento 20,4 , deducido de la serie histórica. Naturalmente, esta proyección debería depurarse en un estudio real;

ch) gasto corriente: se ha supuesto que durante todo el período prospectivo absorbe el 80 por 100 de los Presupuestos municipales;

d) carga de la anualidad: como se ha dicho anteriormente, hemos distinguido tres matices:

- carga potencial: capacidad real de recursos financieros para ser destinados al pago de intereses y amortizaciones derivados de un determinado nivel de endeudamiento;

- carga comprometida: monto de recursos financieros destinados a satisfacer intereses y amortizaciones relativos a préstamos concertados. Se adopta, por tanto, el nivel consolidado en el año 7 (39,3 millones, tabla 2), y

- carga activa (o diferencial): diferencia conceptual (no matemática) entre carga potencial y carga comprometida, para afrontar el servicio de intereses y amortizaciones derivado del endeudamiento actual y del sucesivo. Como es lógico, el monto de la carga de la anualidad activa o diferencial condiciona y define la capacidad inversora con cargo a recursos extraordinarios;

e) inversión real financiada con recursos ordinarios: se obtiene (si aparece) con carácter residual para evitar el "estrangulamiento» que produciría la carga de la anualidad de años anteriores, y

f) inversión real financiada con recursos extraordinarios: resulta por capitalización del monto de la carga de la anualidad activa o diferencial de cada año, es decir, se ha calculado el préstamo neto que cabría obtener mediante la obligación de pagar una can- 
tidad igual a la expresada carga de la anualidad activa o diferencial, al tipo del 7,25 por 100 de interés y una amortización de quince años.

\section{REsultados}

La tabla 9 ofrece los resultados obtenidos por aplicación del esquema operativo descrito. Los recursos totales disponibles para inversión real serían:

$$
\begin{aligned}
& \text { IRO }=0 \\
& \text { IRE }=2.400,9 \text { millones de pesetas } \\
& \text { TOTAL }=2.400,9 \text { millones de pesetas }
\end{aligned}
$$

Como puede observarse, al hacerse IRO $=0$, es decir, al no consignarse en ningún año del período inversión real financiada con recursos ordinarios, se ha supuesto que en ningún momento se "colapsaría» el equilibrio financiero.

No obstante, las cifras de la tabla 9 constituyen sólo un resultado meramente teórico, que refleja un límite ideal de capacidad potencial de recursos financieros del Ayuntamiento, esto es, unas posibilidades abstractas, que en la realidad estarían condicionadas por las prevenciones legales relativas a inversión que pesan sobre los Presupuestos municipales. De ahí que convenga "flexibilizar» el análisis efectuado, de forma que los resultados se acerquen más a la realidad operativa del Ayuntamiento.

\section{CORRECCION DEL MODELO}

Ese mayor acercamiento a la realidad debe discurrir por dos vías distintas, que no se excluyen entre sí. La primera toma en consideración la imposibilidad práctica de prescindir en cualquier caso de la financiación de inversiones reales con recursos ordinarios. La segunda respeta una determinada norma legal, de cumplimiento ineludible en tanto subsista:

a) Una verificación histórica de la inversión realizada con recursos ordinarios (tabla 2) demuestra la paulatina disminución de este componente del gasto a lo largo de todo el período (años 1 al 7). El signo descendente de la inversión con cargo a recursos 
ordinarios guarda una perfecta correlación con el crecimiento de la carga de la anualidad y con la presión ejercida por el gasto corriente, el cual a su vez se incrementa -aparte la influencia de otros factores- por los gastos recurrentes derivados de inversiones anteriores, financiadas tanto con recursos ordinarios como extraordinarios.

b) Por otra parte, el artículo 178 de la Ley sobre Régimen del Suelo y Ordenación Urbana obliga a reservar y afectar una parte de los ingresos que nutren el Presupuesto ordinario para aportarla - transferirla - al Presupuesto especial de Urbanismo a los fines determinados en dicha norma legal.

Paralelamente, pues, a estos dos condicionamientos, la corrección del modelo se ha reflejado en las tablas 10 y 11 bajo dos hipótesis:

- Primera hipótesis (tabla 10):

$\mathrm{IRO}=1$ por 100 sobre $\mathrm{PM}$

- Segunda hipótesis (tabla 11):

IRO $=1$ por 100 sobre $P M+9$ por 100 sobre PO

a). Primera hipótesis.-Aun en el marco de una actuación fundamentada en el propósito de financiar las inversiones reales con recursos extraordinarios, una elemental norma de prudencia (determinada en parte por la historia) aconseja reservar fondos de carácter ordinario para financiar una porción de dichas inversiones.

Siguiendo la misma metodología adoptada en el modelo que se corrige, en la tabla 10 consta el resultado de haber analizado la capacidad potencial de financiación del Ayuntamiento en el supuesto de mantener sólo "al ralentí" la inversión con recursos ordinarios, destinando a esta finalidad únicamente el 1 por 100 de los Presupuestos municipales, para maximizar la capacidad financiera de carácter extraordinario. En tal caso, los recursos totales serían:

IRO $=74,9$ millones de pesetas

IRE $=2.245,8$ millones de pesetas

TOTAL $=2.320,7$ millones de pesetas 
b) Segunda hipótesis.-Del examen de la tabla 11 importa destacar que la posibilidad de obtener recursos extraordinarios aparece en el tercer año del período, como consecuencia de las altas cotas que alcanza la carga de la anualidad y que absorbe el crecimiento previsto de los Presupuestos municipales. Para el primer año del período prospectivo se supone infrautilizar una parte de la carga de la anualidad activa o diferencial, con el objeto de no incrementar el desequilibrio presupuestario que se produce en el año siguiente, es decir:

PM = gasto corriente + carga de la anualidad comprometida + IRO

Así, pues, los recursos totales en esta segunda hipótesis serían:

$$
\begin{aligned}
& \text { IRO }=670,4 \text { millones de pesetas } \\
& \text { IRE }=1.016,7 \text { millones de pesetas }
\end{aligned}
$$

CA activa infrautilizada $=4,1$ millones de pesetas

TOTAL $=1.691,2$ millones de pesetas

Déficit año $9=1,1$ millones de pesetas

\section{CONCLUSION}

Sin duda alguna, el Ayuntamiento contemplado en el presente ejercicio dispondría, con los datos facilitados por el mismo, de una información bastante fiable para adoptar las oportunas decisiones sobre el volumen de las inversiones a realizar y las correspondientes asignaciones de recursos. Lógicamente, se basaría en las previsiones contenidas en la tabla 11.

Tabla 1

EVOLUCION DE LOS PRESUPUESTOS MUNICIPALES

\begin{tabular}{l|c|c|c|c|c|c}
\hline & \multirow{2}{*}{ Años } & & \multirow{2}{*}{ PO } & PU & \multirow{2}{*}{$\begin{array}{c}\text { Aportación } \\
\text { PO a PU }\end{array}$} & \multicolumn{3}{|c}{ T O T A L P M } \\
\cline { 5 - 7 } & 1 & 2 & 3 & $\begin{array}{c}\text { Importe } \\
(1+2-3)\end{array}$ & $\begin{array}{c}\text { Indice } \\
\text { Año base }=100\end{array}$ & \multirow{2}{*}{$\Delta$ Por 100 } \\
\hline 1 & 163,1 & 20,4 & 14,6 & 158,9 & 100,0 & \\
2 & 187,4 & 24,0 & 17,1 & 194,3 & 122,2 & 22,2 \\
3 & 205,3 & 41,0 & 19,0 & 227,3 & 143,04 & 16,9 \\
4 & 216,7 & 47,0 & 20,0 & 243,7 & 153,3 & 7,2 \\
5 & 236,3 & 58,0 & 22,0 & 272,3 & 171,3 & 11,8 \\
6 & 310,6 & 78,5 & 28,0 & 361,0 & 227,2 & 32,1 \\
7 & 426,9 & 95,0 & 38,5 & 483,4 & 304,2 & 33,9 \\
\hline
\end{tabular}

Los valores absolutos, en millones de pesetas. 
Tabla 2

EVOLUCION DE LOS PRESUPUESTOS MUNICIPALES.

DESAGREGACION POR COMPONENTES DEL GASTO

\begin{tabular}{|c|c|c|c|c|c|c|c|c|c|c|c|c|c|c|}
\hline \multirow{3}{*}{ Años } & \multirow{3}{*}{$\begin{array}{c}\text { Total } \\
\text { P M }\end{array}$} & \multicolumn{3}{|c|}{ GASTO CORRIENTE } & \multicolumn{7}{|c|}{ CARGA DE LA ANUALIDAD } & \multicolumn{3}{|c|}{ INVERSION REAL. } \\
\hline & & \multirow[b]{2}{*}{ Importe } & \multirow[b]{2}{*}{$\begin{array}{l}\text { Por } 100 \\
\text { s/total }\end{array}$} & \multirow[b]{2}{*}{$\begin{array}{l}\text { Indice } \\
\text { Año base } \\
=100\end{array}$} & \multicolumn{3}{|c|}{ Intereses } & \multicolumn{3}{|c|}{ Amortizaciones } & \multirow[b]{2}{*}{$\begin{array}{c}\text { Total } \\
\text { agregado }\end{array}$} & \multirow[b]{2}{*}{ Importe } & \multirow[b]{2}{*}{$\begin{array}{l}\text { Por } 100 \\
\text { s/total }\end{array}$} & \multirow[b]{2}{*}{$\begin{array}{l}\text { Indice } \\
\text { Año base } \\
=100\end{array}$} \\
\hline & & & & & Importe & $\begin{array}{l}\text { Por } 100 \\
\text { s/total }\end{array}$ & $\begin{array}{l}\text { Indice } \\
\text { Año base } \\
=100\end{array}$ & Importe & $\begin{array}{l}\text { Por } 100 \\
\text { s/total }\end{array}$ & $\begin{array}{c}\text { Indice } \\
\text { Año base } \\
=100\end{array}$ & & & & \\
\hline 1 & 158,9 & 120,9 & 76,1 & 100,0 & 5,7 & 3,6 & 100,0 & 2,1 & 1,3 & 100,0 & 7,8 & 30,2 & 19,0 & 100,0 \\
\hline 2 & 194,3 & 151,9 & 78,2 & 125,6 & 5,8 & 3,0 & 101,8 & 2,3 & 1,2 & 109,5 & 8,1 & 34,3 & 17,6 & 113,6 \\
\hline 3 & 227,3 & 175,4 & 77,2 & 145,0 & 8,4 & 3,7 & 147,4 & 4,0 & 1,8 & 190,5 & 12,4 & 39,5 & 17,4 & 130,8 \\
\hline 4 & 243,7 & 187,0 & 76,7 & 154,6 & 9,7 & 4,0 & 170,2 & 5,2 & 2,1 & 247,6 & 14,9 & 41,8 & 17,2 & 138,4 \\
\hline 5 & 272,3 & 210,5 & 77,3 & 174,1 & 11,3 & 4,1 & 198,2 & 6,0 & 2,2 & 285,7 & 17,3 & 44,5 & 16,3 & 147,3 \\
\hline 6 & 361,0 & 285,0 & 78,9 & 235,7 & 17,2 & 4,8 & 301,8 & 8,8 & 2,4 & 419,0 & 26,0 & 50,0 & 13,8 & 165,5 \\
\hline 7 & 483,4 & 385,0 & 79,6 & 318,4 & 25,0 & 5,2 & 438,6 & 14,3 & 3,0 & 681,0 & 39,3 & 59,1 & 12,2 & 195,7 \\
\hline
\end{tabular}

Los valores absolutos, en millones de pesetas. 
REVL-1976, núm. 192. ROVIRA MOLA, ALBERTO DE. UN EJERCICIO DE PROGRAMACION FINAN...

Tabla 3

EVOLUCION DEL ENDEUDAMIENTO

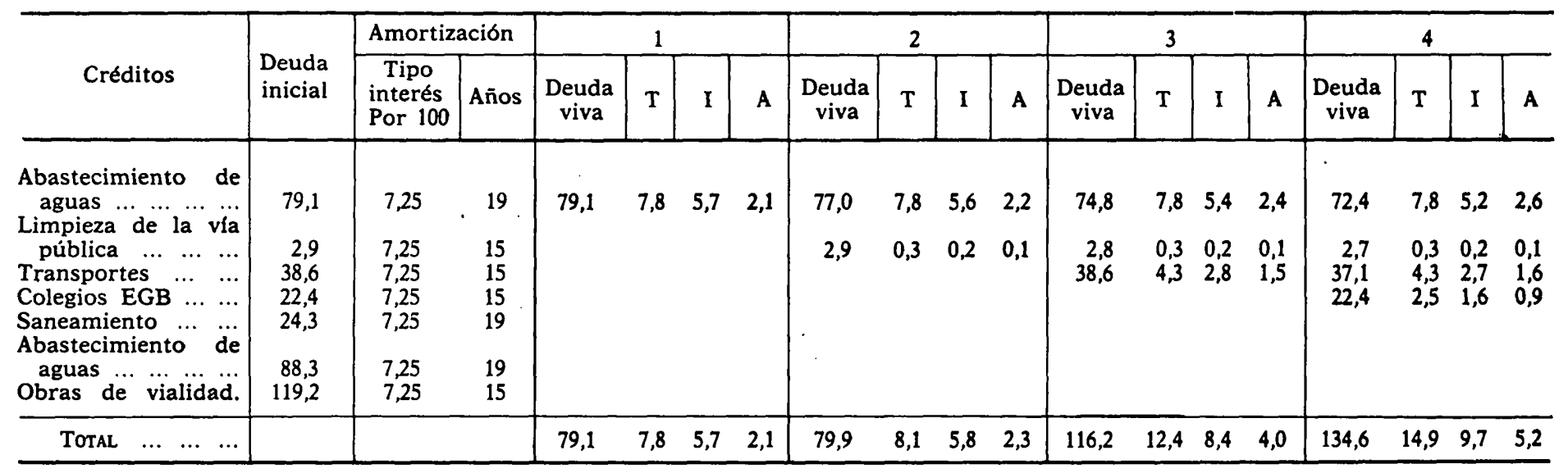

\begin{tabular}{|c|c|c|c|c|c|c|c|c|c|c|c|c|c|c|c|}
\hline \multirow[b]{2}{*}{ Créditos } & \multirow[b]{2}{*}{$\begin{array}{l}\text { Deuda } \\
\text { inicial }\end{array}$} & \multicolumn{2}{|c|}{ Amortización } & \multicolumn{4}{|c|}{5} & \multicolumn{4}{|c|}{6} & \multicolumn{4}{|c|}{7} \\
\hline & & $\begin{array}{l}\text { Tipo } \\
\text { interés } \\
\text { Por } 100\end{array}$ & Años & $\begin{array}{c}\text { Deuda } \\
\text { viva }\end{array}$ & $\mathbf{T}$ & I & $\mathbf{A}$ & $\begin{array}{c}\text { Deuda } \\
\text { viva }\end{array}$ & $\mathrm{T}$ & I & A & $\begin{array}{l}\text { Deuda } \\
\text { viva }\end{array}$ & $\mathbf{T}$ & I & A \\
\hline $\begin{array}{l}\text { Abastecimiento } \\
\text { aguas } \ldots \ldots \ldots \ldots \\
\text { Limpieza de la via }\end{array}$ & 79,1 & 7,25 & 19 & 69,8 & 9,8 & 5,1 & 2,7 & 67,1 & 7,8 & 4,9 & 2,9 & 64,2 & 7,8 & 4,7 & 3,1 \\
\hline 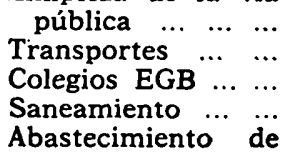 & $\begin{array}{r}2,9 \\
38,6 \\
22,4 \\
24,3\end{array}$ & $\begin{array}{l}7,25 \\
7,25 \\
7,25 \\
7,25\end{array}$ & $\begin{array}{l}15 \\
15 \\
15 \\
19\end{array}$ & $\begin{array}{r}2,6 \\
35,5 \\
21,5 \\
24,3\end{array}$ & $\begin{array}{l}0,3 \\
4,3 \\
2,5 \\
2,4\end{array}$ & $\begin{array}{l}0,2 \\
2,6 \\
1,6 \\
1,8\end{array}$ & $\begin{array}{l}0,1 \\
1,7 \\
0,9 \\
0,6\end{array}$ & $\begin{array}{r}2,5 \\
33,8 \\
20,6 \\
23,7\end{array}$ & $\begin{array}{l}0,3 \\
4,3 \\
2,5 \\
2,4\end{array}$ & $\begin{array}{l}0,2 \\
2,5 \\
1,5 \\
1,7\end{array}$ & $\begin{array}{l}0,1 \\
1,8 \\
1,0 \\
0,7\end{array}$ & $\begin{array}{r}2,4 \\
32,0 \\
19,6 \\
23,0\end{array}$ & $\begin{array}{l}0,3 \\
4,3 \\
2,5 \\
2,4\end{array}$ & $\begin{array}{l}0,2 \\
3,2 \\
1,4 \\
1,6\end{array}$ & $\begin{array}{l}0,1 \\
2,0 \\
1,1 \\
0,8\end{array}$ \\
\hline $\begin{array}{c}\text { aguas } \ldots \\
\text { Obras de vialidad. }\end{array}$ & $\begin{array}{r}88,3 \\
119,2\end{array}$ & $\begin{array}{l}7,25 \\
7,25\end{array}$ & $\begin{array}{l}19 \\
15\end{array}$ & & & & & 88,3 & 8,7 & 6,4 & 2,3 & $\begin{array}{r}86,0 \\
119,2\end{array}$ & $\begin{array}{r}8,7 \\
13,3\end{array}$ & $\begin{array}{l}6,2 \\
8,6\end{array}$ & $\begin{array}{l}2,5 \\
4,7\end{array}$ \\
\hline $\begin{array}{llll}\ldots & \ldots & \ldots\end{array}$ & & & & 153,7 & 17,3 & 11,3 & 6,0 & 236,0 & 26,0 & 17,2 & 8,8 & 396,4 & 39,3 & 25,0 & 14,3 \\
\hline
\end{tabular}

Los valores absolutos, en millones de pesetas. 
Tabla 4 RELACION ENTRE ENDEUDAMIENTO
Y RENTA LOCAL

\begin{tabular}{cccc}
\hline Años & $\begin{array}{c}\text { A } \\
\text { Endeudamiento }\end{array}$ & $\begin{array}{c}\text { B } \\
\text { Renta local }\end{array}$ & $\begin{array}{c}\text { A/B } \\
\text { Por 100 }\end{array}$ \\
\hline 1 & 70,1 & 5.296 & 0,015 \\
2 & 79,9 & 5.667 & 0,014 \\
3 & 116,2 & 6.034 & 0,019 \\
4 & 134,6 & 6.488 & 0,021 \\
5 & 153,7 & 6.942 & 0,022 \\
6 & 236,0 & 7.428 & 0,032 \\
7 & 346,4 & 7.948 & 0,044 \\
\hline
\end{tabular}

Los valores absolutos, en millones de pesetas.

Tabla 5

RELACION ENTRE CARGA DE LA ANUALIDAD

Y PRESUPUESTO ORDINARIO

\begin{tabular}{cccc}
\hline Años & $\begin{array}{c}\text { A } \\
\text { Carga de la } \\
\text { anualidad }\end{array}$ & $\begin{array}{c}\text { B } \\
\text { PO }\end{array}$ & $\begin{array}{c}\text { A/B } \\
\text { Por 100 }\end{array}$ \\
\hline 1 & 7,8 & 153,1 & 5,09 \\
2 & 8,1 & 187,4 & 4,32 \\
3 & 12,4 & 205,3 & 6,04 \\
4 & 14,9 & 216,7 & 6,87 \\
5 & 17,3 & 236,3 & 7,32 \\
6 & 26,0 & 310,5 & 8,37 \\
7 & 39,3 & 426,9 & 9,20 \\
\hline
\end{tabular}

Los valores absolutos, en millones de pesetas.

Tabla 6

RELACION ENTRE CARGA DE LA ANUALIDAD

Y PRESUPUESTOS MUNICIPALES

\begin{tabular}{cccc}
\hline Años & $\begin{array}{c}\text { A } \\
\text { Carga de la } \\
\text { anualidad }\end{array}$ & $\begin{array}{c}\text { B } \\
\text { PM }\end{array}$ & $\begin{array}{c}\text { A/B } \\
\text { Por 100 }\end{array}$ \\
\hline 1 & 7,8 & 158,9 & 4,91 \\
2 & 8,1 & 194,3 & 4,17 \\
3 & 12,4 & 227,3 & 5,45 \\
4 & 14,9 & 243,7 & 6,11 \\
5 & 17,3 & 272,3 & 6,35 \\
6 & 26,0 & 361,0 & 7,20 \\
7 & 39,3 & 483,4 & 8,13 \\
\hline
\end{tabular}

Los valores absolutos, en millones de pesetas. 
Tabla 7

RELACION ENTRE ENDEUDAMIENTO

: Y PRESUPUESTOS MUNICIPALES

\begin{tabular}{cccc}
\hline $\begin{array}{c}\text { Años } \\
\vdots\end{array}$ & $\begin{array}{c}\text { Endeudamiento } \\
\text { PM }\end{array}$ & $\begin{array}{c}\text { B/A } \\
\text { Por } 100\end{array}$ \\
\hline 1 & 79,1 & 158,9 & 2,01 \\
2 & 79,9 & 194,3 & 2,43 \\
3 & 116,2 & 227,3 & 1,95 \\
4 & 134,6 & 243,7 & 1,81 \\
5 & 153,7 & 272,3 & 1,77 \\
6 & 236,0 & 361,0 & 1,53 \\
7 & 346,4 & 483,4 & 1,40 \\
\hline
\end{tabular}

Los valores absolutos, en millones de pesetas.

Tabla 8

RELACION ENTRE' ENDEUDAMIENTO Y CARGA FINANCIERA

\begin{tabular}{|c|c|c|c|}
\hline Años & $\begin{array}{c}\text { A } \\
\text { Carga } \\
\text { financiera }\end{array}$ & Endeudamiento & $\begin{array}{c}\text { A/B } \\
\text { Por } 100\left(^{*}\right)\end{array}$ \\
\hline 1 & 5,7 & 79,1 & 7,25 \\
\hline 2 & 5,8 & 79,9 & 7,25 \\
\hline 3 & 8,4 & $116 ; 2$ & 7,25 \\
\hline 4 & 9,7 & 134,6 & 7,25 \\
\hline 5 & 11,3 & 153,7 & 7,25 \\
\hline 6 & 17,2 & 236,0 & 7,25 \\
\hline 7 & 25,0 & 346,4 & 7,25 \\
\hline
\end{tabular}

Los valores absolutos, en millones de pesetas.

$\left(^{\star}\right)$ Cifras expresadas por redondeo. 


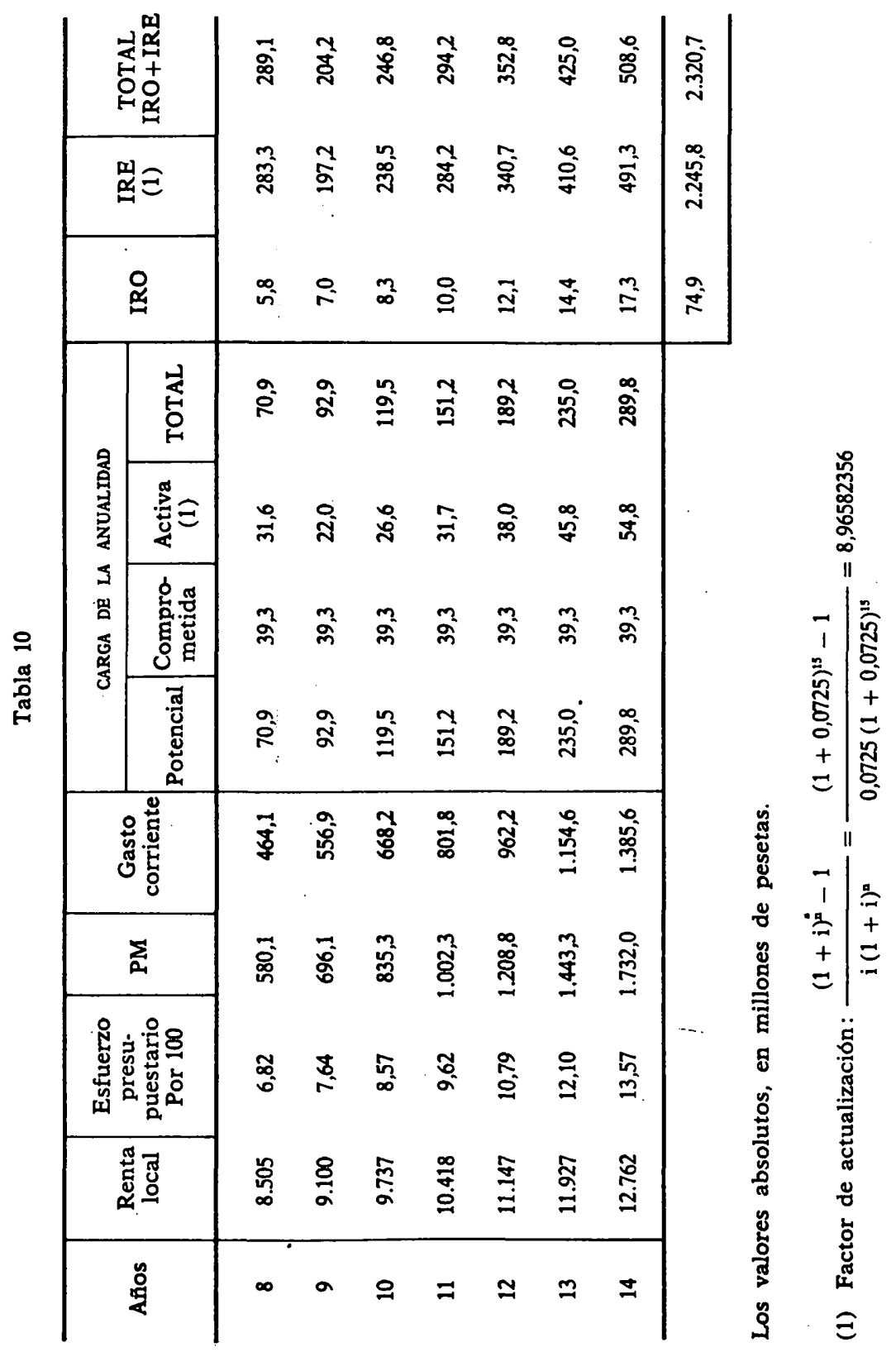


Tabla 11

\begin{tabular}{|c|c|c|c|c|c|c|c|c|c|c|c|c|c|}
\hline Affos & $\begin{array}{l}\text { Renta } \\
\text { local }\end{array}$ & $\begin{array}{c}\text { Esfuerzo } \\
\text { presu- } \\
\text { puestario } \\
\text { Por } 100\end{array}$ & $\mathbf{P M}$ & $\begin{array}{c}\text { Gasto } \\
\text { corriente }\end{array}$ & Potencial & $\begin{array}{l}\text { Compro- } \\
\text { metida }\end{array}$ & $\begin{array}{c}\text { Activa } \\
\text { (1) }\end{array}$ & TOTAL & $\begin{array}{c}1 \text { por } 100 \\
\text { s/PM }\end{array}$ & $\begin{array}{c}9 \text { por } 100 \\
\text { s/PO }\end{array}$ & TOTAL & $\underset{(1)}{\operatorname{IRE}}$ & $\begin{array}{c}\text { TOTAL } \\
\text { RECUR } \\
\text { SOS }\end{array}$ \\
\hline 8 & 8.505 & 6,82 & 580,1 & 446,1 & 43,1 . & 39,0 & $(4,1)$ & 39,0 & 5,8 & 46,1 & 51,9 & - & 56,0 \\
\hline 10 & 9.737 & 8,57 & 835,3 & 668,2 & 53,4 & 39,0 & 14,4 & 53,4 & 8,3 & 66,4 & 74,7 & 129,1 & 203,8 \\
\hline 11 & 10.418 & 9,62 & $1.002,2$ & 801,8 & 71,8 & 39,0 & 18,4 & 71,8 & 10,0 & 79,7 & 89,7 & 165,0 & 254,7 \\
\hline 12 & 11.147 & 10,79 & $1.208,8$ & 962,2 & 99,9 & 39,0 & 28,1 & 99,9 & 12,1 & 95,6 & 107,7 & 251,9 & 359,6 \\
\hline
\end{tabular}

Los valores absolutos, en millones de pesetas.

(1) Factor de actualización: $\frac{(1+i)^{n}-1}{i(1+i)^{n}}=\frac{(1+0,0725)^{13}-1}{0,0725(1+0,0725)^{15}}=8,96582356$

(*) Déficit previsto, 1,1 millones de pesetas.

( ) Carga de la anualidad diferencial infrautilizada. 


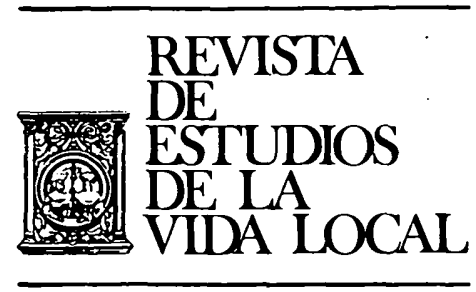

\section{CRONICAS}


REVL-1976, núm. 192: ROVIRA MOLA, ALBERTO DE. UN EJERCICIO DE PROGRAMACION FINAN... REVL-1976, núm. 192. ROVIRA MOLA, ALBERTO DE. UN EJERCICIO DE PROGRAMACION FINAN... 